\title{
Hydrodynamic Modelling and Analysis of a New-developed Mobile Refrigerated Container
}

\author{
László Kátai*, Tibor Várszegi*, István Oldal*, László Zsidai** \\ *Szent István University, Faculty of Mechanical Engineering, Institute of \\ Mechanics and Machinery, Páter K. u. 1, 2100 Gödöllö, Hungary, e-mail: \\ katai.laszlo@gek.szie.hu,varszegi.tibor@gek.szie.hu,oldal.istvan@gek.szie.hu \\ **Szent István University, Faculty of Mechanical Engineering, Institute of \\ Industrial Technologies, Páter K. u. 1, 2100 Gödöllő, Hungary, e-mail: \\ zsidai.laszlo@gek.szie.hu
}

\begin{abstract}
In this paper the hydrodynamic air flow relations in two adjustable compartment units of the mobile refrigerated container were examined. Analytical solution of the hydrodynamic equations describing the cooling air flow motion is not possible. We applied two possible methods for the solution: (1) - small scale test, (2) - approximate solution of the ordinary differential equations with finite elements simulation. The objective of the performed tests is to define the cooling air flow kinematical conditions, such as air velocity distribution in empty and fully loaded state, testing the shape of the air inlet profile and furthermore to determine the necessity of auxiliary ventilators adaptation. According to the performed test results a proposal to the final development of the cooling and ventilation elements has been made.
\end{abstract}

Keywords: cfd analysis; refrigerated container; small scale test; 3D model; FEM

\section{Introduction}

Due to HACCP requirements the storage and transportation of food products and food raw materials at a suitable temperature is an extremely important issue in logistics. Currently, the availability of technical solutions regarding the transportation part of the cooling chain is limited; the use of transportation vehicles with refrigerated cargo holds is the most common. However, even if for a short time, the cooling chain can be compromised due to technical deficiencies and human error. The solution to the technical deficiencies is the design of intelligent refrigerated compartments to be implemented in the project. One of the conditions of efficient and reliable refrigeration for the whole load is evenly distributed flow in the whole compartment. 
In this article we have examined air flow distribution in the newly-designed mobile refrigerated container compartments, for which work the background is provided by the research and development GOP project consortium.

\subsection{The Structure and Operation of the Designed Cooling Container}

Extensive international literature deals with container transportation and the structure of containers. $[1 \ldots 3,7,8]$ The selected container type determines the whole transportation system since emission level functions of different pollutants are also applicable as route costs of transportation assignment problems, thus taking fuel consumption and environmental impact into account during process design. [6, 9]

The designed container shown in Figure 1 can be loaded via both ends, it is suitable for road and rail transportation, it is 20 feet long, with 2 temperature settings, adjustable compartments, and assembled with a diesel refrigeration unit.

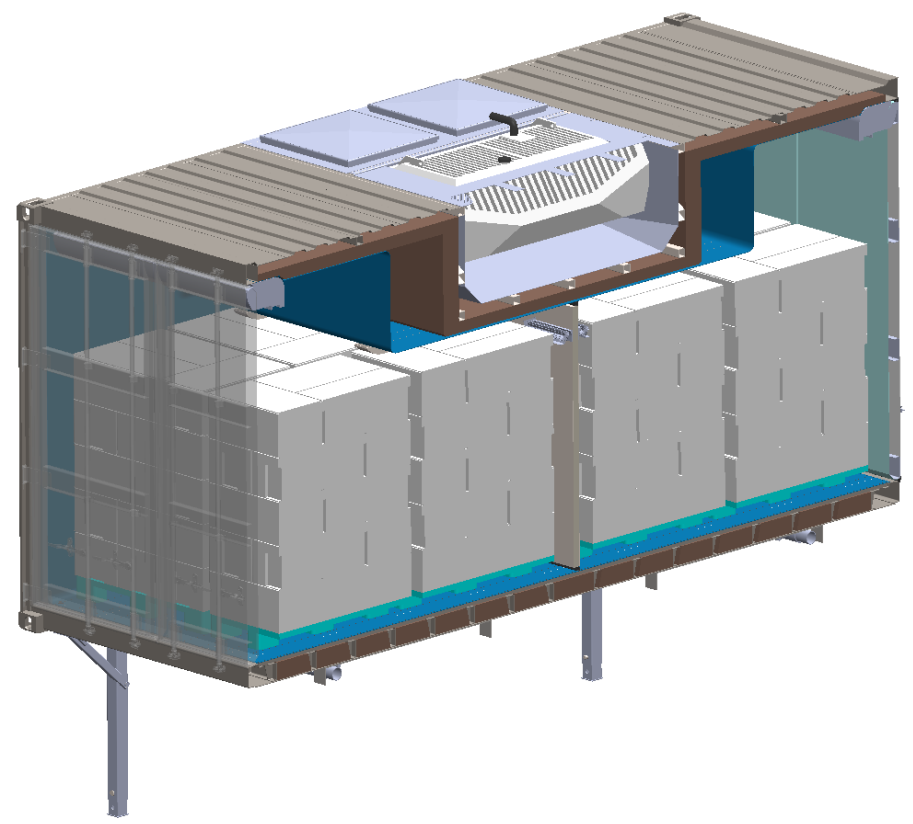

a) 


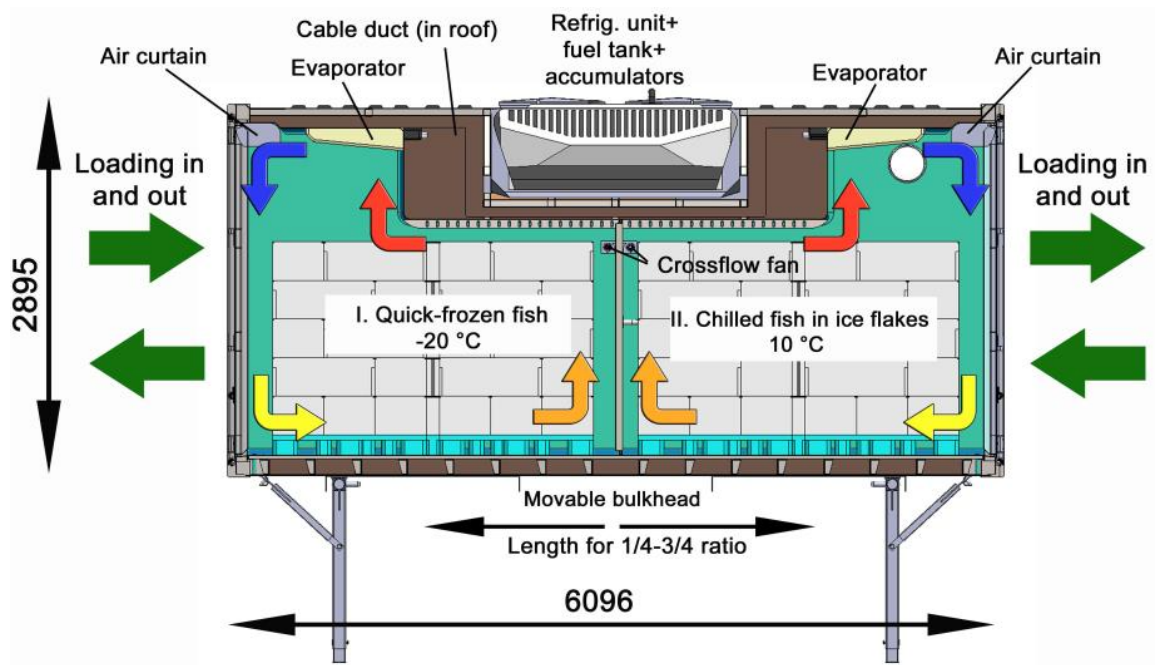

b)

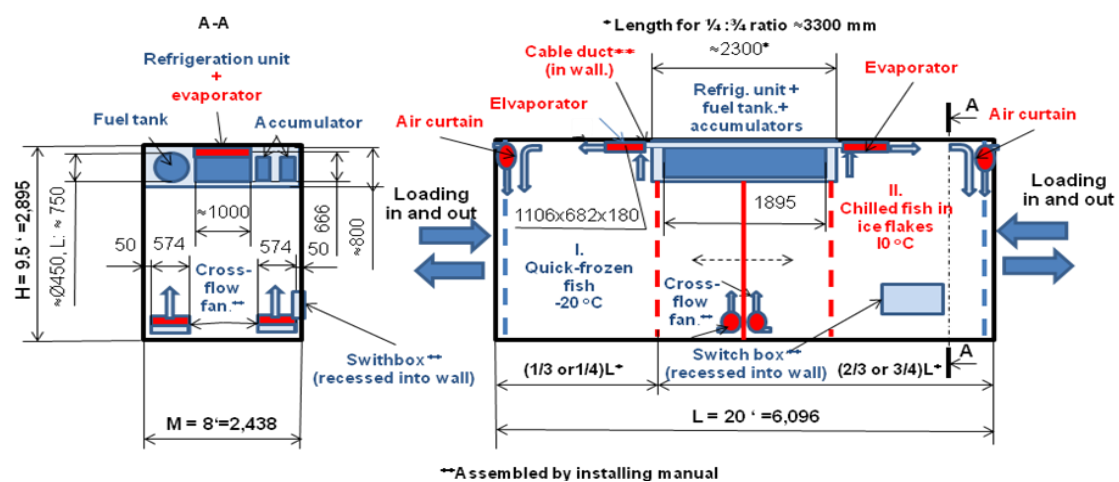

c)

Figure 1

a) A Perspective view of the container b) The cooling characteristics, flow directions c) The diagram of the cooling system and air circulation

Its main characteristics: (1) - own diesel engine for refrigeration unit, (2) - 2 refrigeration compressors (one diesel unit + a second electrical one for stand-by state), (3) - cross flow air cooling of condenser of the refrigeration unit relative to the direction of travel of the vehicle, (4) - refrigeration unit is located in the gravity axis of the container, (5) - easy accessibility of the refrigeration units to assemble and maintain them, (6) - installation of DC cross flow fans, (7) - double air curtains, (8) - installed with GPS positioning and temperature transmitter. The applied 3 cylinder 4-cycle liquid cooled $0.854 \mathrm{~L}$ diesel engine has a $16 \mathrm{~kW}$ maximum output power (at $3600 \mathrm{rpm}$ ). Due to its overall dimensions ( $\mathrm{LxWxH}$ $518 \times 454 \times 576 \mathrm{~mm}$ ) it can easily fit into the space and has been designed in the 
middle section of the container roof. The diesel drive of the refrigeration unit makes the cooling of compartments independent of the speed and direction of travel of the vehicle and can be even used in the stand-by position. The independent diesel engine consumes less fuel and reduces the impact on the environment. The installation of two separate refrigeration compressors increases the safety of refrigeration transportation. The dual energy supply (diesel and electrical) makes the refrigeration system more flexible and makes it possible (in stand-by state) to specify and modify the type of driving power depending on the cost of energy sources. Owing to the cross direction position of the condensing unit relative to the direction of travel of the vehicle the operation of refrigeration unit becomes independent of the direction of travel of the vehicle $[4,5]$. Due to the mounting of the refrigeration unit and its accessories in the gravity axis of the container the route traceability of the vehicle is safer. The refrigeration unit and its accessories can be accessed by a built-in telescopic ladder so they can be assembled and maintained on the spot and can also be removed. The cross flow fans making the airflow more uniform within the container spaces are located and fixed on the movable bulkheads, they can be moved along with the bulkheads, and can be powered by DC accumulators both in road and stand-by state. The temperature of compartments is decreased by about 10 degrees centigrade by the application of the double air curtains when the container is opened for loading in and out. The GPS system makes it possible to track the route, the mobile and stand-by position of the vehicle, its fuel consumption and the temperature of the compartments, furthermore if the refrigerated mobile container breaks down; it helps organize a rescue action.

Due to the "unique" design of the container it had become obvious that the establishment of the flow conditions of the (cooling) air was not possible through analytical mathematical methods. Therefore, in order to justify the "concept" "plank" (experimental model) measurements and finite-element simulation were performed. Numeric simulation is used by Son H. Ho et al. (2010) to examine the flow conditions of cooling air for cooling-houses with good results [10]. Several studies deal with CFD temperature distribution analysis of refrigerated containers $[11,12]$.

\section{Material and Method}

\subsection{Tools of Affinity Experiments}

The measurements were taken in the controlled temperature range - Tc $=(0 \div 2){ }^{\circ} \mathrm{C}$ - with cooled air, while in the laboratory the temperature of the ambient air surrounding the experimental model was: $\mathrm{Ta}=23{ }^{\circ} \mathrm{C}$. 
The experimental model simulates one of the compartments of the container to be developed in which air of $\mathrm{T}_{\text {air }}=(0 \div 2){ }^{\circ} \mathrm{C}$ temperature circulates. For this, i.e. to create the experimental model the existing FRIGOR - BOX type cooling chamber, recommended for $\mathrm{T}=(0 \div 2){ }^{\circ} \mathrm{C}$ temperature was used.

The ratio of the plank model (experimental model):

$$
\mathrm{i}=2226 / 1140=1,952 \sim 2
$$

This resulted from the fact that the width of the experimental model chamber was the same as the original width of the FRIGOR - BOX cooling chamber, which was: $\mathrm{sk}=1140 \mathrm{~mm}$.

Figure 2 shows the structure and the main components of the experimental model.

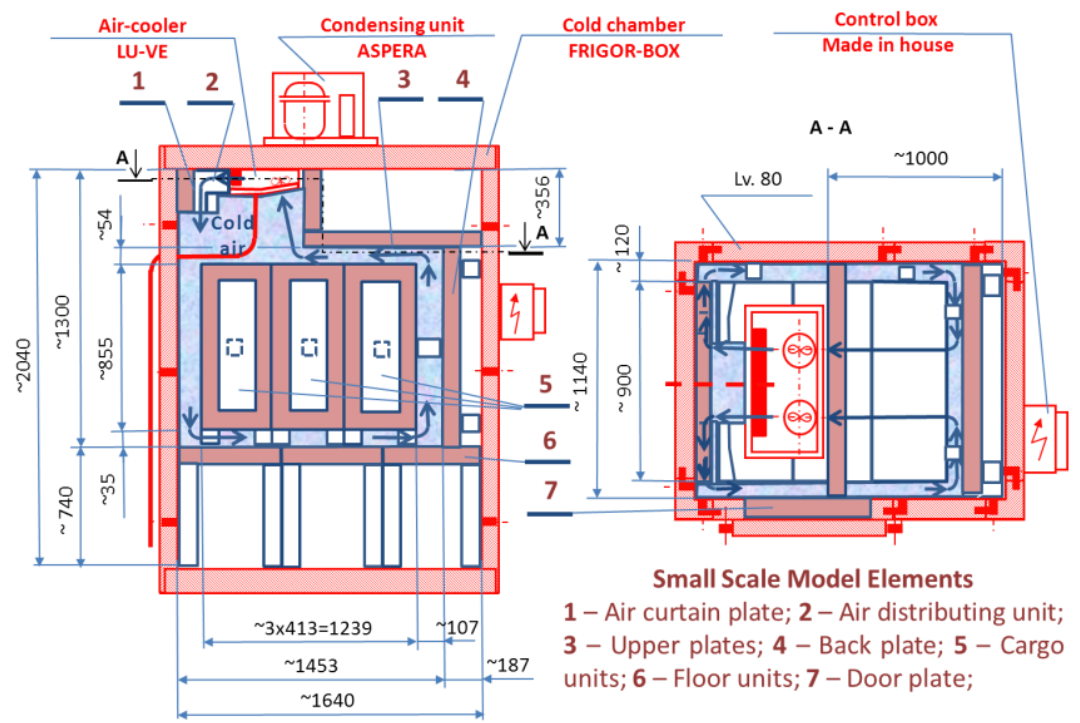

Figure 2

The sketch, dimensions and components of the experimental model

The construction of the plank model (experimental model) (see Figure 2): was made by converting the FRIGOR - BOX cooling chamber, by inserting walls from Styrofoam components. The width of the cargo hold of the experimental model was identical to the original width of the cooling chamber, sk $=\mathrm{sm}$. However, the shape, the height (hk) and the length (lk) of the original cooling chamber was different from the shape and the dimensions calculated above of the prototype in the original development concept and the corresponding plank (experimental model): $[\mathrm{hk}>(\mathrm{hm}+\mathrm{hmb})]$, and $(\mathrm{lk}>\mathrm{lm})$. Therefore, an upper plate (3), back plate (4), floor unit (6) and door plate (7) - to eliminate the door recess were built into the original chamber. With this, a cargo hold corresponding to the shape of the prototype cooling chamber and dimensions corresponding to the size reduction were generated on the plank model (experimental model). 
In the plank model the velocity of the air flowing in the gaps between the plank model and the cargo model was measured by a TESTO 435 anemometer. The test kit contained both thermal (hot wire) and wheel sensors which could be connected to a common measuring, display and data recording unit.

The thermal (hot wire) sensor measured air temperature in addition to air velocity.

The measurement points were determined in the middle of the gaps of the experimental model, in the midline of the width of the two outer cargo models, at the same distance from the corners, on one side of the longitudinal symmetry line of the experimental model because the refrigerated container is symmetric to its longitudinal axis. It was assumed that in the other (mirror image) part the flow pattern and the velocities were identical. The marking of the measuring points is shown in Figure 3/a, their location, coordinates are shown in Figure 3/b. In the case of the marking of the measurement location: the number marks the serial number of the gap, the corresponding index marks the serial number of the bore. The number of measurement points: 12 , the number of bores: 16 , because in the horizontal gaps the velocities in the direction of axes " $x$ " and " $y$ " must be measured through two separate bores. The bores were plugged in with plastic pipe caps when not being measured.

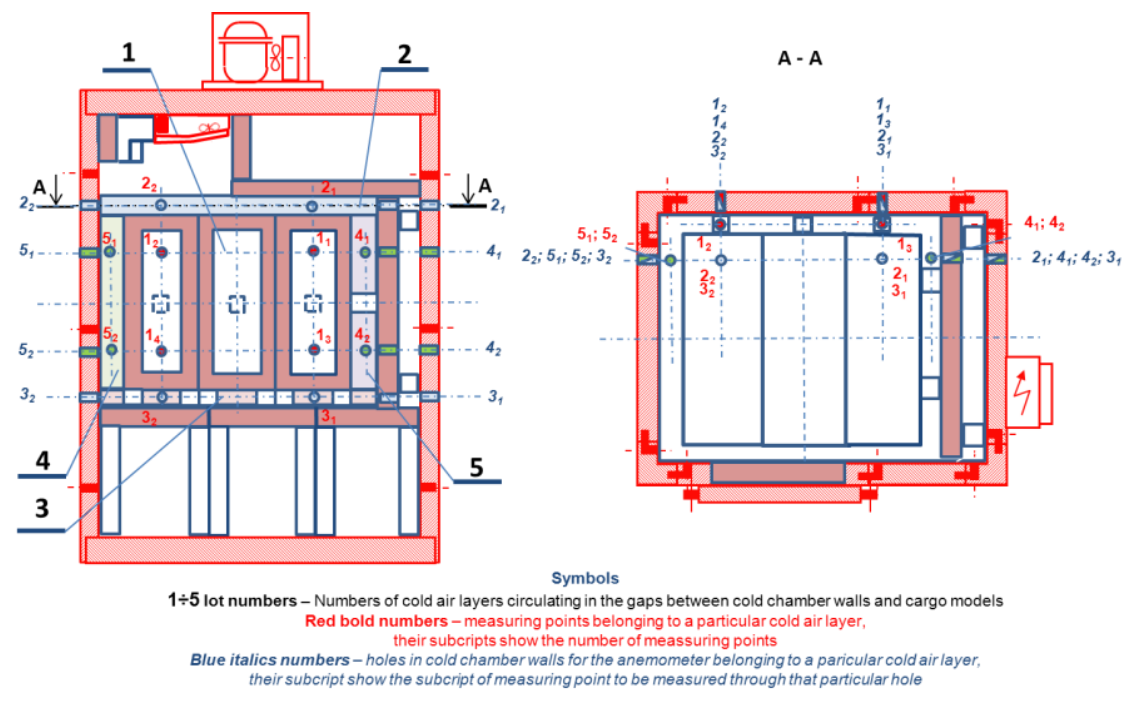




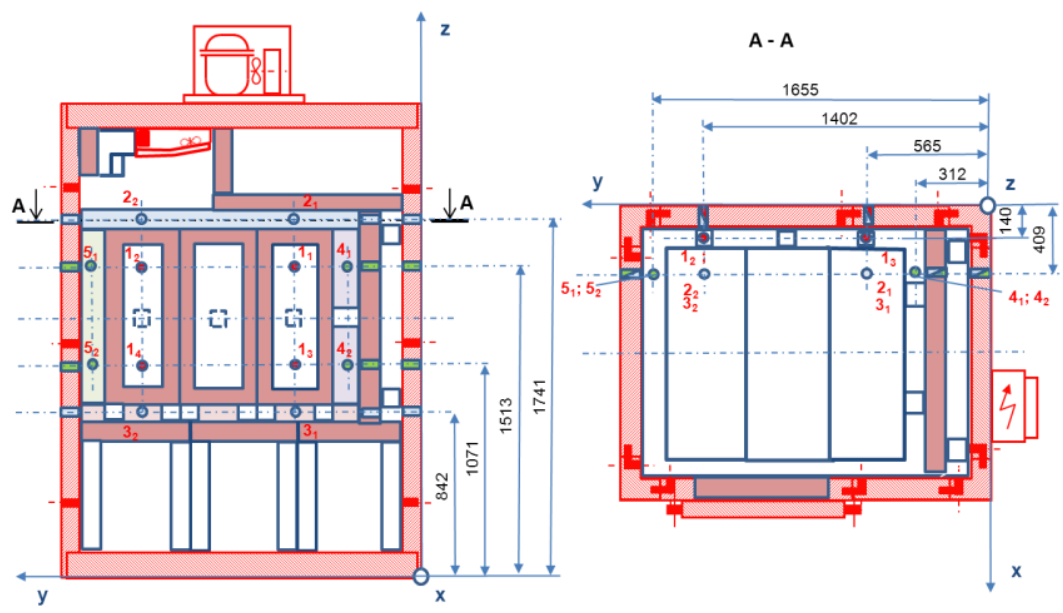

b)

Figure 3

a) Marking of the measurement points and the inlet of the sensors, b) Coordinates of the measuring points and the bores serving as inlet and fixing for the sensors

\subsection{Method of the Experimental Model Experiment}

The velocity of the air distributed and circulated by the fan of the cooling equipment was measured in the gaps between the experimental model (plank model) and the cargo model - in the direction of space coordinates " $x$ ", " $y$ " and "z".

\subsubsection{The Examination of Similarity}

The cooling air flows in the gap between the inner walls of the refrigerated container and the cargo in all the - i.e. $\mathrm{x}-\mathrm{y}-\mathrm{z}-$ directions of space. Physical similarity was expressed with the identical Reynolds (Rem) number - Rep $=$ Rem of the prototype (Rep) and the gaps of the experimental model [13, 14, 15, 16]. This can be defined with the equation of the Reynolds number as:

$$
\operatorname{Re}_{\mathrm{p}}=\left(\mathrm{d}_{\mathrm{p}} \times \mathrm{v}_{\mathrm{p}}\right) / v=\operatorname{Re}_{\mathrm{m}}=\left(\mathrm{d}_{\mathrm{m}} \times \mathrm{v}_{\mathrm{m}}\right) / v
$$

where: $v$ is the kinematic viscosity of air, which is the same on the prototype and in the case of the experimental model, so it drops out of the equation,

$d_{p}$ and $d_{m}$ - the identical diameter of the gaps on the prototype ( $\mathrm{p}$ - index), and on the experimental model $(\mathrm{m}-$ index $), \mathrm{m}$,

$\mathrm{v}_{\mathrm{p}}$ and $\mathrm{v}_{\mathrm{m}}$ - the flow velocities in the gaps on the prototype ( $\mathrm{p}$ - index) and on the experimental model $(\mathrm{m}-$ index $), \mathrm{m} / \mathrm{s}$. 
Mentioned before, the cooling media (cold air) used had the same temperature both in the experimental model and the prototype. Thus, the "Pr" number (Prandtl number) of the cooling media is, also, the same in both cases:

$$
\operatorname{Pr}_{\mathrm{p}}=\left(\mathrm{c}_{\mathrm{p}} \times \mu\right) / \mathrm{k}=\operatorname{Pr}_{\mathrm{m}}
$$

Where: $\mathrm{P}_{\mathrm{rp}}$ and $\mathrm{P}_{\mathrm{rm}}$ - Prandtl number for cooling air in prototype $(\mathrm{p}-$ index) and in experimental model $(\mathrm{m}-$ index $)$

$\mathrm{c}_{\mathrm{p}}$ - specific heat at constant pressure, $\mathrm{kJ} / \mathrm{kg} \mathrm{K}$

$\mu$ - Dinamic viscosity, $\mathrm{Pa} \mathrm{s}$

$\mathrm{k}$ - thermal conductivity, $\mathrm{W} / \mathrm{m} \mathrm{K}$

In order for the results of the hydrodynamic experiments conducted on the experimental model to be transferred to the prototype, the "geometric" and "physical (flow)" similarity between the experimental model and the prototype equipment is fundamental. The experimental model was created and the measurements taken were performed in light of these principles $[17,18]$.

\subsection{The Method of the Hydrodynamic Simulation}

The steady state of hydrodynamic modelling is examined. This means the cargo is in the compartment, the door is closed, the cooling unit is working continuously and at a constant output. The freezer and cooling compartments are examined together, from a hydrodynamic point of view with almost identical geometries identical, hydrodynamic state is assumed. The geometries must be examined one by one in the case of each partition wall position. In the longest case, which is the most unfavourable from a hydrodynamic point of view, it is examined for several aspects [19].

Geometric modelling

During geometric modelling the inside air is modelled, all connected bodies are considered as outer contour. The body and the peripheral conditions are also symmetric, so it is sufficient just to model half of the body and the other half is modelled with symmetry peripheral condition (green in the figure). (Except in the case of asymmetric cargo because then the model of the entire body is needed.) 


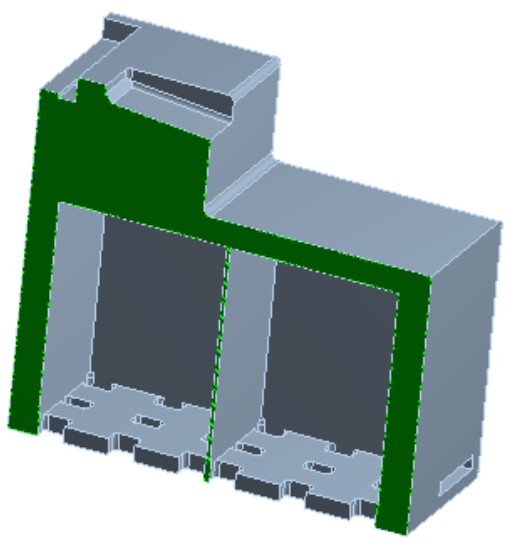

Figure 4

Geometric model of the examined space

Finite-element modelling

In the case of hydrodynamic simulation another important part of modelling is breaking down to elements. With modelling in addition to the mesh of the necessary size the special background layer mesh is also necessary along the walls.

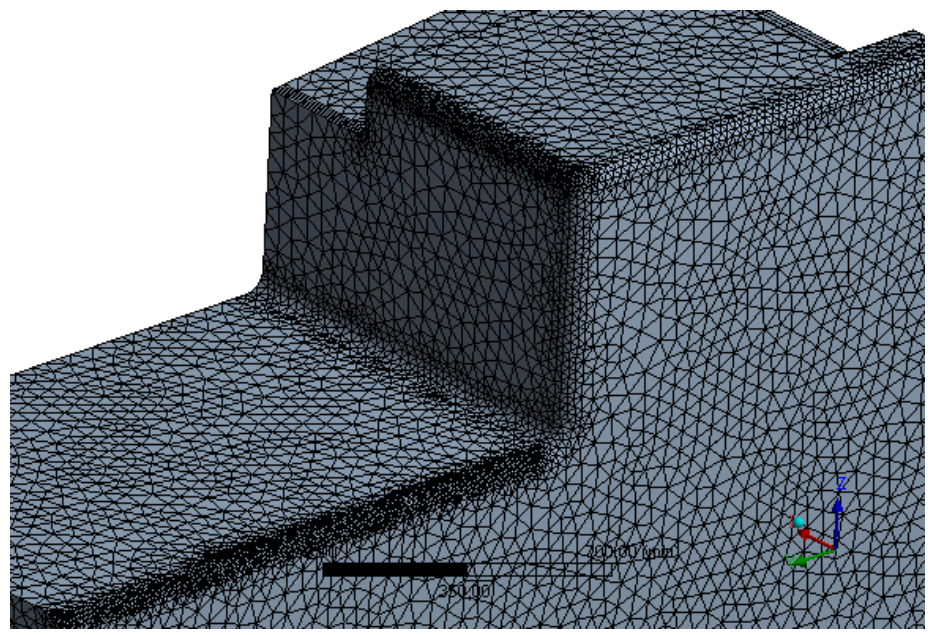




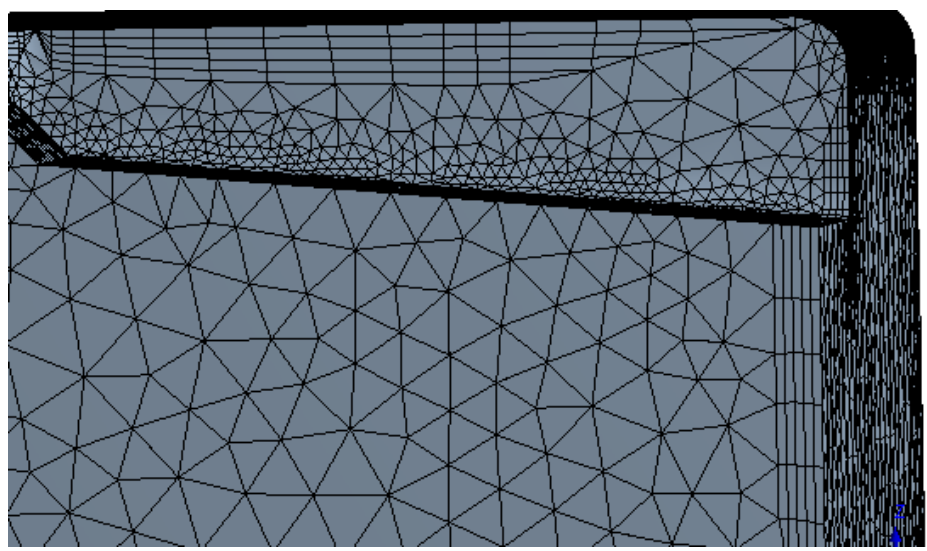

Figure 5

Boundary layer mesh

When modelling the environment, the air flowing in and out of the cooling unit as well as the air flowing in and out of the auxiliary fan, furthermore, the symmetry and the wall impact must be also considered. The modelling of the wall impact is shown in Figure 6.

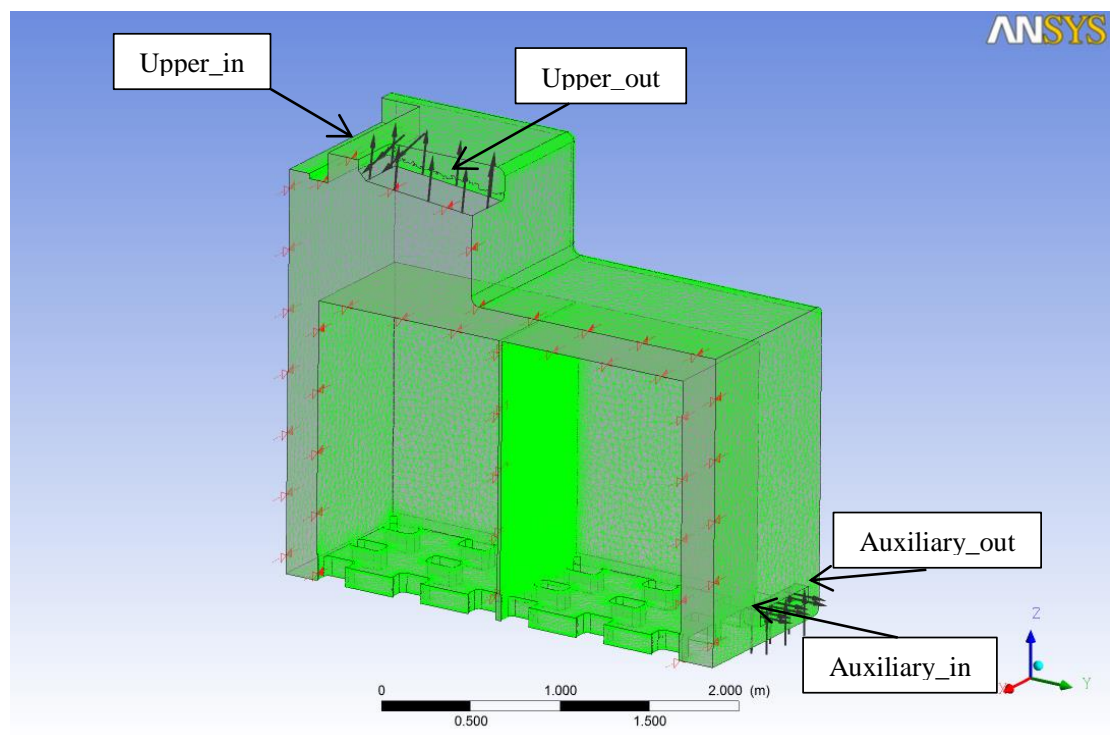

Figure 6

Modelling the wall impact

The material and the settings of the simulation (e.g. the turbulence model) are given in the following table: 
Table 1

Simulation settings

\begin{tabular}{|l|l|}
\hline \multicolumn{2}{|c|}{ Materials } \\
\hline Air at 25 C & Material Library \\
\hline Fluid Definition & Continuous Fluid \\
\hline Morphology & \\
\hline &
\end{tabular}

\begin{tabular}{|l|c|}
\hline \multicolumn{2}{|c|}{ Settings } \\
\hline Buoyancy Model & Non Buoyant \\
\hline Domain Motion & Stationary \\
\hline Reference Pressure & $1.0000 \mathrm{e}+00[\mathrm{~atm}]$ \\
\hline Heat Transfer Model & Isothermal \\
\hline Fluid Temperature & $25[\mathrm{C}]$ \\
\hline Turbulence Model & k epsilon \\
\hline Turbulent Wall Functions & Scalable \\
\hline
\end{tabular}

The boundary conditions was set according to the following table:

Table 2

Boundary conditions

\begin{tabular}{|c|c|}
\hline \multicolumn{2}{|c|}{ Boundaries } \\
\hline Boundary & -Upper_in \\
\hline Location & INLET \\
\hline \multicolumn{2}{|c|}{ Settings } \\
\hline Flow Regime & Upper_in \\
\hline Mass And Momentum & Normal Speed \\
\hline Normal Speed & 9.5000e+00 [m s^-1] \\
\hline Turbulence & Medium Intensity and Eddy Viscosity \\
\hline \multicolumn{2}{|c|}{ Ratio } \\
\hline Type & INLET \\
\hline Location & Auxiliary_in \\
\hline \multicolumn{2}{|c|}{ Settings } \\
\hline Flow Direction & Normal to Boundary Condition \\
\hline Flow Regime & Subsonic \\
\hline Mass And Momentum & Mass Flow Rate \\
\hline Mass Flow Rate & 5.2900e-02 [kg s^-1] \\
\hline Turbulence & Medium Intensity and Eddy Viscosity \\
& Ratio \\
\hline
\end{tabular}




\begin{tabular}{|c|c|}
\hline \multicolumn{2}{|c|}{ Boundary - Upper_out } \\
\hline Type & OUTLET \\
\hline Location & Upper_out \\
\hline Flow Regime Settings \\
\hline Mass And Momentum & Subsonic \\
\hline Mass Flow Rate & Mass Flow Rate \\
\hline \multicolumn{1}{|c|}{ Boundary - Auxiliary_out } \\
\hline Type & OUTLET \\
\hline Location & Auxiliary_out \\
\hline \multicolumn{2}{|c|}{ Settings } \\
\hline Flow Regime & Subsonic \\
\hline Mass And Momentum & Mass Flow Rate \\
\hline Mass Flow Rate & 5.2900e-02 [kg s $\left.{ }^{\wedge}-1\right]$ \\
\hline
\end{tabular}

Since the container has a movable partition wall, in the case of the studied space part simulation was performed for several geometric settings (position of the bulkhead). The layout of the studied cases is illustrated in Figure 7.

The aim was to determine the flow velocities in the whole geometry for the listed cases. The boundary conditions of the simulation were set up in the following way:

- The evaporator fans perform the blowing in; the particulars of the evaporator fan:

- $\quad$ opening: about $88 \times 600 \mathrm{~mm}$

- airflow: about. $1680 \mathrm{~m} 3 / \mathrm{h}$

- blow-in velocity: $9.5 \mathrm{~m} / \mathrm{s}$

- throw distance: about $7.5 \mathrm{~m}$

- type: 2 axial fans, pressure: about $50 \mathrm{~mm} \mathrm{H}_{2} \mathrm{O}$

- Auxiliary fans:

type: 2 ZIEHL-ABEGG QR 06A-50BP 90o, cross-flow fan airflow: $610 \mathrm{~m} 3 / \mathrm{h}$.

Accordingly, the boundary conditions were given in the following way:

- evaporator blow-in velocity: $9.5 \mathrm{~m} / \mathrm{s}$,

- $\quad$ suction side of evaporator $1680 \mathrm{~m} 3 / \mathrm{h}$ air flow $=0.5883 \mathrm{~kg} / \mathrm{s}$, only half of this is modelled due to the use of the symmetry, thus the airflow: 0.29167 $\mathrm{kg} / \mathrm{s}$,

- auxiliary fans: $610 \mathrm{~m} 3 / \mathrm{h}=0.2118 \mathrm{~kg} / \mathrm{s}$ on both the outlet and inlet side. 
There are three simulations for each geometric model:

- the auxiliary fans are at the bottom of the partition wall,

- the auxiliary fans are at the top of the auxiliary fans,

the auxiliary fans are not switched on.

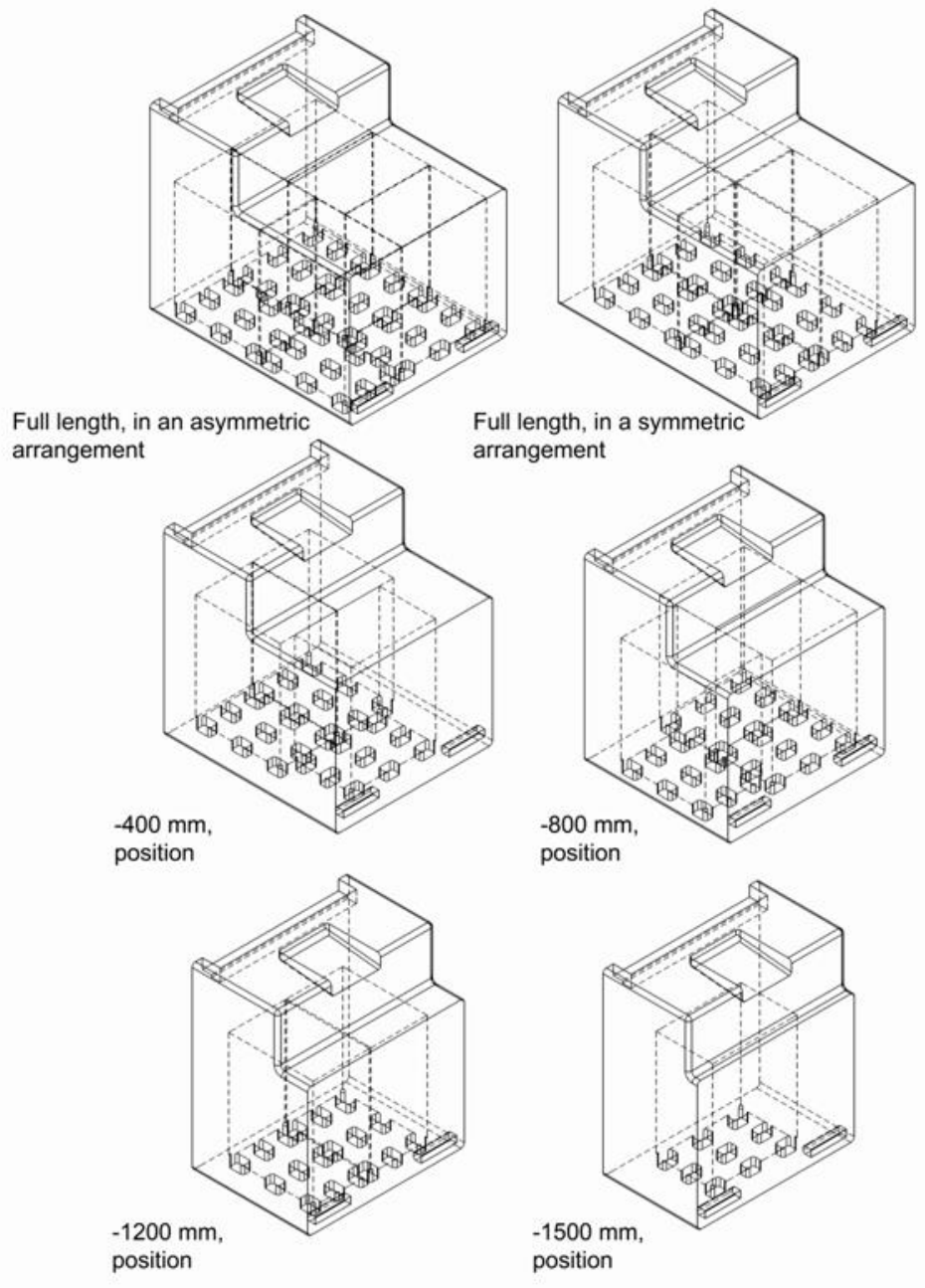

Figure 7

Layouts of the studied inner space 


\section{Results and Discussion}

\subsection{Results, Findings of the Experimental Model Experiment}

During the measurement the following were modified:

- the "loadedness" of the experimental model, which means that measurements were taken in two states - loaded (with cargo model) and unloaded (without cargo model),

- thedelivery of the fan $(\mathrm{V})$ and the velocity of the blow-in $\left(\mathrm{v}_{\mathrm{o}}\right)$.

The measurement parameters are summarized in Table 1.

Table 1

Measurement settings

\begin{tabular}{|c|c|c|c|}
\hline $\begin{array}{c}\text { Serial number of } \\
\text { the measurement } \\
\text { setting }\end{array}$ & $\begin{array}{c}\text { Delivery of the fan } \\
(\mathrm{V}) \mathrm{m}^{3} / \mathrm{h}\end{array}$ & $\begin{array}{c}\text { Blow-in velocity of } \\
\text { the air }\left(\mathrm{v}_{\mathrm{o}}\right) \mathrm{m} / \mathrm{s}\end{array}$ & $\begin{array}{c}\text { Loadedness of the } \\
\text { experimental model }\end{array}$ \\
\hline 1 & 850 & 4.75 & $\begin{array}{c}\text { empty (without } \\
\text { cargo) }\end{array}$ \\
\hline 2 & 850 & 4.75 & loaded \\
\hline 3 & 651 & 3.64 & loaded \\
\hline
\end{tabular}

The circulation of the air in the gaps in the symmetry planes

The profile of the air flow velocity is determined from the test results of each measurement setting around the experimental model cargo in the gaps in the symmetry planes "xy", "xz" and "yz" perpendicular to each other - going through the centre of gravity of the cargo model. The illustration of the symmetry planes is shown in Figure 8. It is determined how the air velocity changes while it goes around the gaps in these symmetry planes, from being blown out of the fan until being suctioned in the fan, during the circulation occurring in the given plane. For a better visual representation, the speed profiles derived from the measurement data are illustrated graphically, in figures. 


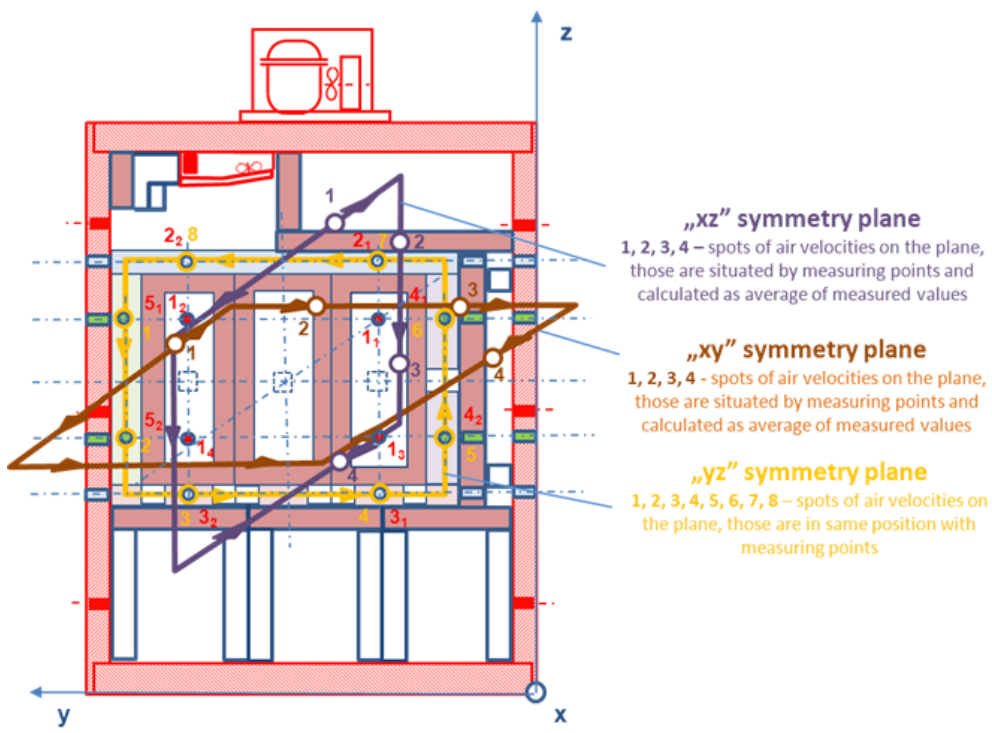

Figure 8

Interpretation of the symmetry planes, the gaps and the flow (circulation) directions.

As an example, Figure 9 shows the measured speed profiles in the case of measurement setting 1 .

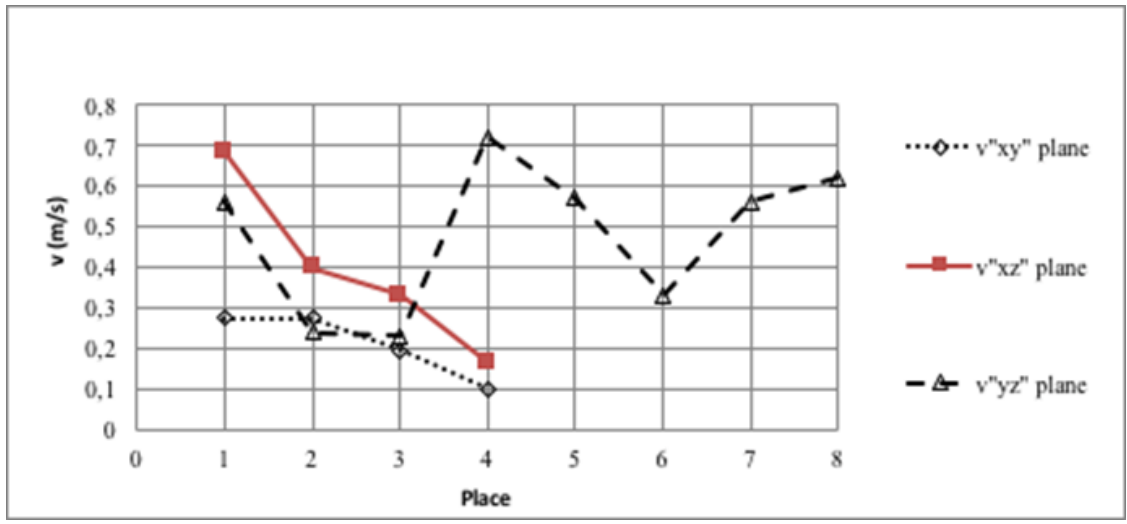

Figure 9

Profile of the air flow velocity: in symmetry plane "xy",in symmetry plane "xz", in symmetry plane "yz",with empty experimental model

Figure 10 shows the results obtained from measurement setting 2, and Figure 11 shows the results obtained from measurement setting 3 . 


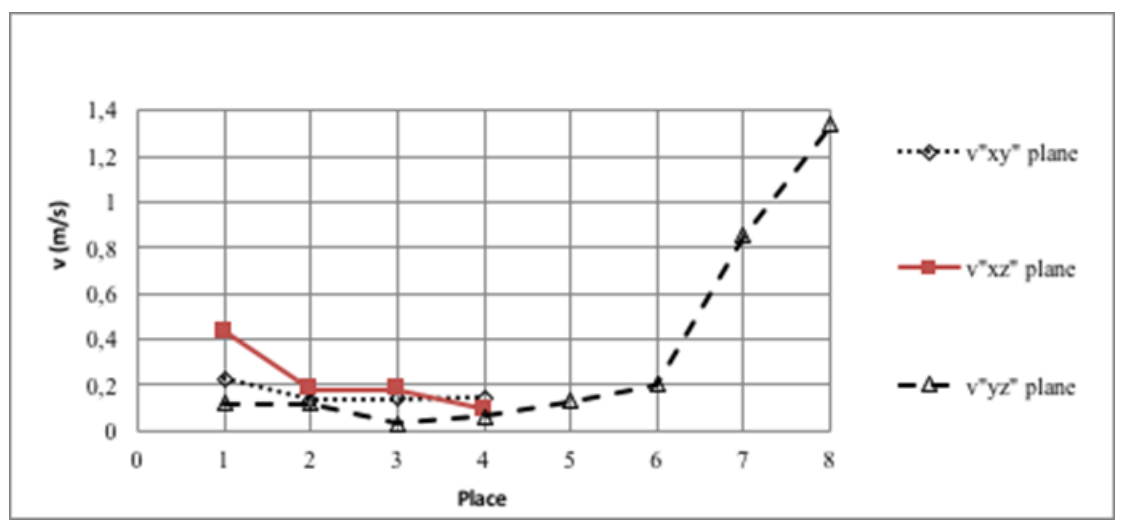

Figure 10

Profile of the air flow velocity:in the gap in symmetry plane "xy", in the gap in symmetry plane " $x z$ ", in the gap in symmetry plane "yz", in loaded state with delivery rate of $V_{2}=850 \mathrm{~m}^{3} / \mathrm{h}$

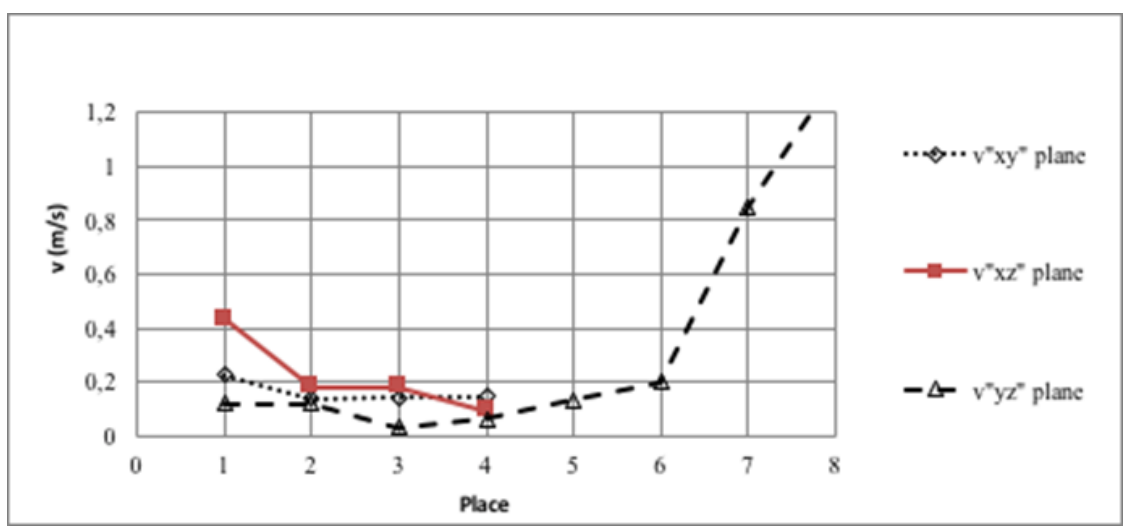

Figure 11

Profile of the air flow velocity:in the gap in symmetry plane "xy",in the gap in symmetry plane "xz",in the gap in symmetry plane "yz", in loaded state with delivery rate of $V_{3}=651 \mathrm{~m}^{3} / \mathrm{h}$

General findings:

The thermal anemometer used for measuring the velocities and temperatures showed significantly varying air velocities many times in the same points, furthermore, it showed slightly different temperatures in the same points, but turned into different directions. Therefore, in the case of both parameters the average values are included in the figures showing the evaluation.

The alternation, change of the velocities and the temperatures can be explained by the turbulent flow of the air. Since the measurement points in the experimental model are situated "relatively" near the corners of the cargo hold, turbulent flow was "expected". 
Based on the temperatures measured during the tests which fluctuated between 0 and $10{ }^{\circ} \mathrm{C}$ it can be concluded that the air only cooled down to the value $\mathrm{T}_{\text {air, }}=(0$ $\div 2)^{\circ} \mathrm{C}$ set on the thermostat near sensor " $\mathrm{A}$ " of the evaporator. Elsewhere, it was much warmer than this, which can be explained by the fact that the walls making up the cargo hold of the experimental model and the cargo model did not cool down to the above temperature, so they projected heat energy into the air. This also influenced the air flow, but the deviances caused by the temperature differences of cooling air were negligible for the calculation of the results, see physical parameters of air in reference of Kiss R. (1980) [20].

At the same time, the results measured for temperature have indicated that socalled "heat recesses (temperature peaks)" can come into effect in the compartments of the container, furthermore underlined the importance of proper pre-cooling of both the compartments and the cargo prior to loading in, separately.

For solving the problems caused by fluctuating and not proper air temperature, on one hand a new telemetric system has been developed in the project and that among others applied several temperature sensors locating in the area of temperature peaks to control the refrigeration system. Those devices are not discussed and prescribed in the current paper.

On the other hand, for improving air circulation affectivity and blowing cold air into the "heat recess areas", new additional duct + nozzle system and two auxiliary fans were built in each compartment of the prototype container. Principles of the newly developed elements will be illustrated and described in the section titled "Conclusions".

\subsection{Results of the Hydrodynamic Simulation}

Velocity distributions were examined in horizontal plane. One specific test result is shown in Figure 12.

A too low flow velocity is unfavourable in terms of heat distribution, harmful to the quality of cooling. A too high flow velocity increases the cooling power demand. Since in our case the quality of cooling is important, the primary aim is to avoid too low velocities. With the actual fans the maximum velocity does not change in a wide range anyway, so its impact is less significant. During the tests velocity values lower than $0.5 \mathrm{~m} / \mathrm{s}$ are examined, velocities lower than this can only occur on small, local surfaces, which can assure refrigerated transportation of proper quality.

The results are summarized in Table 2 . 


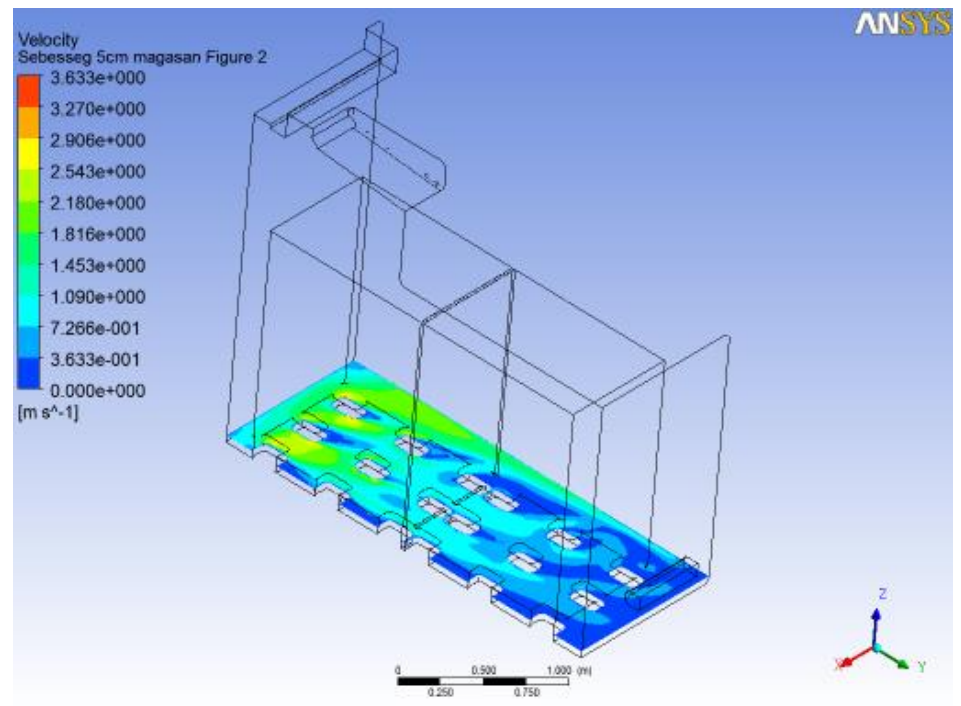

Figure 12

Full length, symmetrical arrangement, without auxiliary fan, in the case of horizontal blow-in the velocity distribution at the feet of the pallets

Table 2

Measurement results

\begin{tabular}{|l|c|c|}
\hline & v max & $\begin{array}{c}\text { \% of areas of velocity } \\
\text { lower than } 0.5 \mathrm{~m} / \mathrm{s}\end{array}$ \\
\hline Asymm, full, no auxiliary fan & 2.025 & 50 \\
\hline Symm, full, no auxiliary fan & 5.576 & 15 \\
\hline Symm, -400, no auxiliary fan & 6.6 & 5 \\
\hline Symm, -800, no auxiliary fan & 3.651 & 15 \\
\hline Symm, -1200, no auxiliary fan & 5.38 & 70 \\
\hline Asymm, full, upper auxiliary fan & 2.12 & 10 \\
\hline Symm, full, upper auxiliary fan & 7.393 & 10 \\
\hline Symm, -400, upper auxiliary fan & 6.817 & 10 \\
\hline Symm, -800, upper auxiliary fan & 4.92 & 5 \\
\hline Symm, -1200, upper auxiliary fan & 6.435 & 20 \\
\hline Asymm, full, lower auxiliary fan & 2.247 & 5 \\
\hline Symm, full, lower auxiliary fan & 5.411 & 5 \\
\hline Symm, -400, lower auxiliary fan & 6.792 & 5 \\
\hline Symm, -800, lower auxiliary fan & 4.879 & 3 \\
\hline Symm, -1200, lower auxiliary fan & 6.722 & 40 \\
\hline Symm, full, with horizontal blow-in & 3.633 & 10 \\
\hline $\begin{array}{l}\text { Symm, full, with horizontal blow-in, } \\
\text { lower auxiliary fan }\end{array}$ & 4.097 & \\
\hline
\end{tabular}


Based on the measurements it can be concluded that the most unfavourable layout is the longest cooled space with symmetrical cargo arrangement. The results of this case are shown in Figure 13.

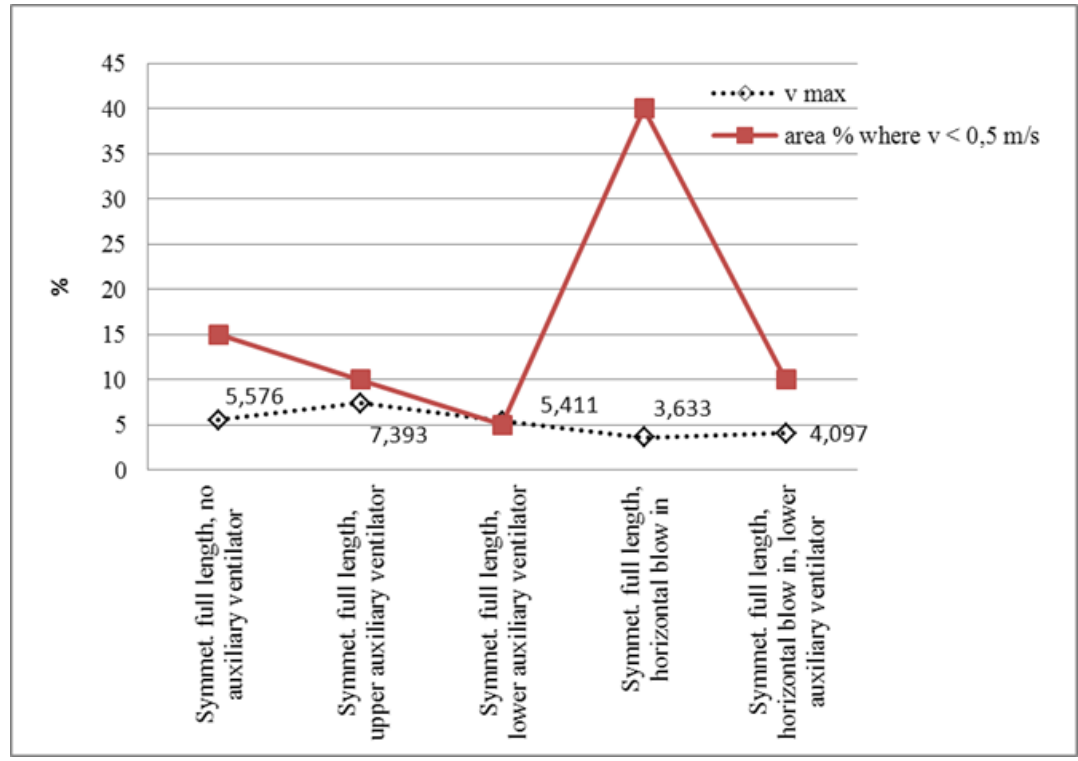

Figure 13

Longest cooled space, the maximum air velocities with symmetrical cargo arrangement, and the ratio of areas of velocity lower than $0.5 \mathrm{~m} / \mathrm{s}$

The ratio of areas of velocity lower than $0.5 \mathrm{~m} / \mathrm{s}$ was examined. At lower air velocities than this local thermal bridges may be generated, which adversely affect the quality of cooling, so this value must be reduced to the lowest possible state. In reality the situation is somewhat more favourable than the calculation because simulation assumes a steady state, which does not exist due to the well visible turbulences, so air movement is more intensive in areas where low velocity and high velocity areas are next to each other. It can be concluded that horizontal blow-in is unsuitable to generate proper air movement. $40 \%$ of the area air velocity is too low, which is detrimental in itself, as opposed to the next case there is another problem here that the area is coherent, i.e. there is an almost stationary zone in the middle of the container, so there is no cooling. This can be modified with an auxiliary fan to an acceptable level, as the last pair of results show.

As a comparison Figure 14 shows the results with the shortest cooling compartment setting. It can be concluded that in the case of this small space already the air movement generated by the properly directed condensing unit is sufficient to achieve the proper cooling quality. Spaces shorter than this were not tested, it is apparent the flow conditions are better and better in smaller spaces, as it had been expected. 


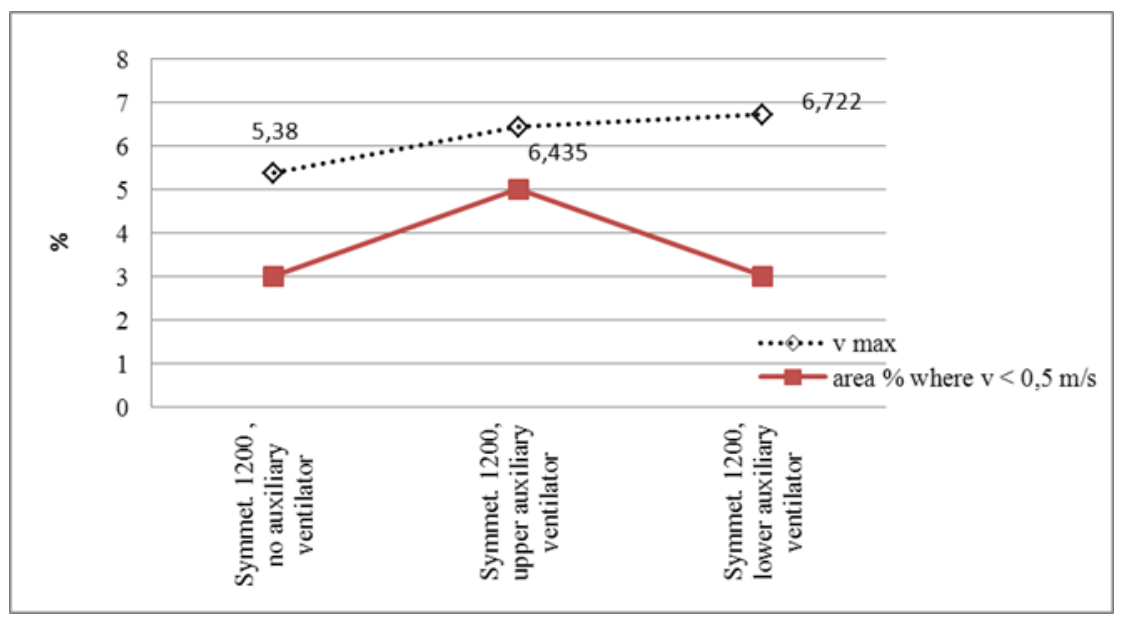

Figure 14

Shortest cooled space,the maximum air velocities with symmetrical cargo arrangement, and the ratio of areas of velocity lower than $0.5 \mathrm{~m} / \mathrm{s}$

\section{Conclusions}

With the original design of the condensing unit the container is not suitable for proper cooling with all the cooling space arrangements. Due to the horizontal blow-in the suitable air circulation is not generated. This is supported by the experimental model experiments in addition to the simulations.

The application of the multijet technology with several auxiliary fans and directed evaporator blow-out is required to assure optimum quality of cooling.

The auxiliary fans at the top position improve the flow with little efficiency and increase the maximum speed, so their application does not provide any obvious advantages.

The optimum position of the auxiliary fans is the bottom of the partition wall. The flow assistance effect is the most efficient; the uniformity of the flow is, also the best in this way.

The increase in the throw of the air could be supported by the previously proposed auxiliary fans and the use and installation of the air distribution unit containing the jets. Figure 15 shows a proposal for the construction of this. 


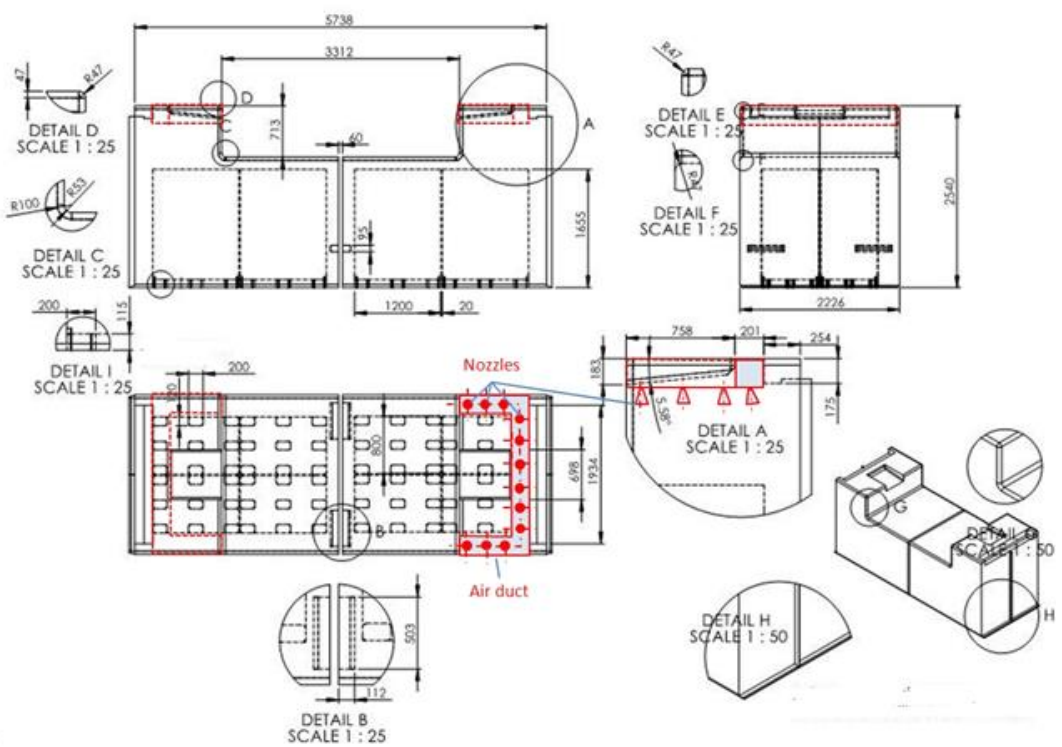

Figure 15

Sketch of the installation of the air distribution unit featuring the blow-in jet nozzles (throw jet nozzles)

\section{Acknowledgement}

This work was supported by the GOP-1.1.1.-11-2012-0322 identification number project titled: "Research and development of new type intelligent mobile refrigerated compartments with multi-dimension and injection airflow technique and GPS registration."

Among the authors, László Zsidai would like to thank MTA (Hungarian Academy of Sciences) for supporting this work in the frame of the research fellowship BOLYAI (BO/00127/13/6).

\section{References}

[1] Prezenszki J. (et.al.): Logistics II. Logistics Development Centre, 1999

[2] Scharnow, U./Scharnow, R.: Container, Gutart und Qualitätserhaltungwährend des Seetransports [Container, type of cargo and retention of quality during maritime transport] (Part 1) DDR-Verkehr, Berlin 19 (1986) 1, pp. 20-23; Continuation and conclusion 19 (1986) 2, pp. $50-55$

[3] Grote-Antonson: Handbook of Mechanical Engineering: ISBN 9783540 49131 6; Springer, New York, 2008

[4] Beke Gy.: Freezing Industrial Handbook Vol. I, Mezőgazda Kiadó, Budapest 2001 
[5] Várszegi T.: Food Industrial Technologies and Machines. Szent István University, Gödöllö, 2009

[6] Edit Schmidt: Elementary Investigation of Transportation Problems. Acta Polytechnica Hungarica Vol. 6, No. 2, 2009, ISSN 1785-8860

[7] Kasmire, R. F. and Hinsch, R. T. (1987) Maintaining Optimum Transit Temperatures in Refrigerated Truck Shipments of Perishables. University of California Perishables Handling Transportation Supplement No. 2

[8] Y. Wild: Containerhandbuch. GDV 2014.1500 p.

[9] A. Csikós et al.: Real-Time Estimation of Emissions Emerging from Motorways Based on Macroscopic Traffic Data. Acta Polytechnica Hungarica Vol. 8, No. 6, 2011, ISSN 1785-8860

[10] Son H. Ho, Luis Rosaria, Muhammad M. Rahman: Numerical Simulation of Temperature and Velocity in a Refrigerated Warehouse. International Journal of Refrigeration Vol. 32, pp. 1015-1025 (2010) ISSN 0140-7007

[11] Yuta Umeno et al: The Use of CFD to Simulate Temperature Distribution in Refrigerated Containers. Engineering in Agriculture, Environment and Food, Vol. 8, Issue 4, October 2015, pp. 257-263, ISSN: 1881-8366

[12] Thijs Defraeye et al: Integral Performance Evaluation of the Fresh-Produce Cold Chain: A Case Study for Ambient Loading of Citrus in Refrigerated Containers. Postharvest Biology and Technology Vol. 112, 2016, pp. 1-13, ISSN: 0925-5214

[13] Holman, J. P. (1992) Heat Transfer. McGraw-Hill Book Company. Singapore

[14] Al-Shemmeri, T. T. (2012) Engineering Fluid Mechanics. www.bookboon.com. E-book

[15] Fejes, G. és Fábry, Gy. (1975) Vegyipari Gépek és Műveletek II Tankönyvkiadó, Budapest

[16] Fejes, G. és Tarján, G. (1973) Vegyipari Gépek és Mủveletek. Tankönyvkiadó, Budapest

[17] Tijskens, L. M. M. - Hertog, M. L. A. T. M. - Nicolaï (2001) Food Process Modelling. Woodhead Publishing Ltd. Cambridge, England

[18] Liu, C. (2012) Advances in Modeling of Fluid Dynamics. www.ebooksdirectory.com. E-book

[19] Nakasone, Y. - Stolarski, T. A. - Yoshimoto, S. (2006) Engineering Analysis with ANSYS Software. ELSEVIER. E-book

[20] Kiss, R. (1980) Légtechnikai Adatok. Müszaki Könyvkiadó, Nudapest 